\title{
OPTIMIZATION AND EVALUATION OF CHLORPHENIRAMINE MALEATE ORAL STRIP FOR PEDIATRIC USE
}

\author{
SURA ZUHAIR MAHMOOD, HIBA SABAH SABRY, NORA ZAWAR YOUSIF*, ZEINA D SALMAN \\ Department of Pharmaceutics, College of Pharmacy, Mustansiriyah University, Baghdad, Iraq. \\ Email: pharm.nora.zawar@uomustansiriyah.edu.iq \\ Received: 08 July 2018, Revised and Accepted: 25 October 2018
}

\section{ABSTRACT}

Objective: The goal of performing this study is to prepare an oral strip, especially designed for pediatric use that provides fast onset of action with ease of swallowing particularly for young individuals who suffer from difficulty of swallowing, in addition provides maximum therapeutic effectiveness by reducing the first pass effect.

Materials and Methods: The oral strip was prepared by solvent casting technique through using different sole polymers (hydroxypropyl methylcellulose [HPMC] 15cp, HPMC 50cp, polyvinyl alcohol, and sodium carboxymethyl cellulose). Maltodextrin (MD) was added as the secondary polymer in different ratios to optimize the release parameters, and disintegration time (DT), three different plasticizers were employed (propylene glycol, dibutyl phthalate, and glycerin) to boost the film forming polymer characteristics.

Results: From this study, it is obvious that F10 which composed of HPMC as a main polymer and MD as a secondary polymer in ratio 2:1, respectively, provides adequate physicochemical characteristics, in vitro/in vivo DT DT (40/36 s), respectively, nevertheless a satisfactory release parameters as (59.9\%) released at $2 \mathrm{~min}$ and $80 \%$ of drug released at $14.8 \mathrm{~min}$.

Conclusion: The optimized formula is pretty encouraging to originate an oral strip that provides ease of administration, fast onset of action with wide acceptance for the pediatric population.

Keywords: Oral, Strip, Pediatric, Ease of swallowing, Hydroxypropyl methylcellulose, Maltodextrin.

(C) 2018 The Authors. Published by Innovare Academic Sciences Pvt Ltd. This is an open access article under the CC BY license (http://creativecommons. org/licenses/by/4. 0/) DOI: http://dx.doi.org/10.22159/ajpcr.2018.v11i12.28985

\section{INTRODUCTION}

Oral route is the most preferential route of delivering the drug to the systemic circulation due to low cost and simplicity of administration that leads to enhance in patient compliance $[1,2]$.

Many pediatric and geriatric patients are unwilling to take solid preparations, the problem of swallowing is a common phenomenon due to fear of choking, dysphasia and also in young individuals due to underdeveloped muscular and nervous systems as in schizophrenic patients which lead to poor patient compliance [3,4]. Fast dissolving strip as a delivery system consists of a thin, elegant films of edible water-soluble polymers simply placed on the patient's tongue without the intake of water, instantly wet by minor amount of saliva then the strip rapidly disintegrates and dissolves to release the medication for oral mucosal absorption, to overcome the difficulties in swallowing the conventional oral dosage $[5,6]$.

Due to the simplicity of administration, this technology developed over the past few years to become a novel and widely accepted form by consumers [7].

Numerous ideal characteristics of a drug to be used in preparing fast dissolving strip such as: The drug should have acceptable taste; small to moderate molecular weight is desirable, good stability and solubility in water because manufacturing requires solvents and heat for drying [8].

Chlorpheniramine maleate is a first-generation alkylamine antihistamine used in the prevention of the symptoms of allergic conditions such as rhinitis and urticaria. Antihistamines are widely available as both prescription and over-the-counter products for the treatment of allergies, runny nose, sneezing, itching, and watery eyes caused by allergies, the common cold, and flu $[9,10]$.

Chlorpheniramine maleate is typically administered 2-3 times daily. The drug is readily and rapidly absorbed from the gastrointestinal tract, but the oral bioavailability is about $25-40 \%$ due to high firstpass metabolism, as the drug is largely inactivated in the liver and the metabolites excreted in the urine; therefore, the onset of action is slow. So there is a need to formulate a dosage form which gives fast relief from allergic conditions and improves the bioavailability of drug, therefore; fast dissolving strip is the best choice $[11,12]$.

\section{MATERIALS AND METHODS}

\section{Materials}

Chlorpheniramine Maleate and Mannitol were obtained from (Samara drug industry-Iraq) HPMC ( $15 \mathrm{cp}, 50 \mathrm{cp}$ ), Na CMC, PVA were obtained from (Provizerpharma-India), Maltodextrin was obtained from (Sigma-Aldrich- USA), Glycerin was obtained from (GCC-UK), Citric acid, Propylene glycol was purchased from (Panreac-Espana), Sodium saccharine was purchased from (Avonchem limit-UK), di butyl phthalate was purchased from (Fluka Chemika, Switzerland). All other reagents and chemicals used were of analytical grade.

\section{Methods}

Preparation of oral strip

Ten formulas were prepared (F1-F10), using a solvent casting method with different types of polymers and plasticizers, the composition is shown in Table 1. Drug, sodium saccharin, citric acid, mannitol, and plasticizers (glycerin, PG) were dissolved in a suitable volume of water except for the third type of plasticizer (DBT) in which $10 \mathrm{ml}$ of $3 \%$ acetic acid was used to solubilize it, with heating and continuous 
Table 1: Ingredients used in the preparation of chlorpheniramine maleate pediatric oral strips

\begin{tabular}{|c|c|c|c|c|c|c|c|c|c|c|}
\hline Ingredients & F1 & F2 & F3 & F4 & F5 & F6 & F7 & F8 & F9 & F10 \\
\hline Chlorpheniramine Maleate & 2 & 2 & 2 & 2 & 2 & 2 & 2 & 2 & 2 & 2 \\
\hline HPMC15ср & 48 & & & & 48 & 48 & 48 & 24 & 16 & 32 \\
\hline HPMC50cp & & 48 & & & & & & & & \\
\hline PVA & & & 48 & & & & & & & \\
\hline $\mathrm{Na} C M C$ & & & & 48 & & & & & & \\
\hline MD & & & & & & & & 24 & 32 & 16 \\
\hline DBP & & & & & 25 & & & & & \\
\hline Glycerin & & & & & & 25 & 20 & 25 & 25 & 25 \\
\hline Sodium saccharin & 4 & 4 & 4 & 4 & 4 & 4 & 4 & 4 & 4 & 4 \\
\hline Citric acid & 2 & 2 & 2 & 2 & 2 & 2 & 2 & 2 & 2 & 2 \\
\hline Mannitol & 19 & 19 & 19 & 19 & 19 & 19 & 24 & 19 & 19 & 19 \\
\hline
\end{tabular}

HPMC: Hydroxypropyl methylcellulose, PVA: Polyvinyl alcohol, Na CMC: Sodium carboxymethyl cellulose, PG: Propylene glycol, DBP: Dibutyl phthalate, MD: Maltodextrin

stirring to form a clear solution. After cooling, a suitable amount of polymers (an aqueous preparation of film-forming polymer was separately arranged) was added to the previously prepared solution with continuous stirring for $4 \mathrm{~h}$, until uniformly viscous solution achieved, which was kept un-disturbed for $24 \mathrm{~h}$ to remove the entrapped air. The resulting solution was poured into a $9 \mathrm{~cm}$ Petri dish and allowed to dry in hot air oven at $40^{\circ} \mathrm{C}$ for $24 \mathrm{~h}$, the dried batch carefully removed and cut into 16 desired size strips, each strip has a surface area approximately of $4 \mathrm{~cm}^{2}(2 \mathrm{~cm} \times 2 \mathrm{~cm})$ and loaded with $2 \mathrm{mg}$ of chlorpheniramine maleate [13-15].

\section{Evaluation of oral strips}

Visual inspection

Properties such as homogeneity, color, transparency, and surface of the oral strips were inspected for all the prepared oral strips [16].

Thickness measurements

The thickness of the strip was measured by a micrometer screw gauge at different strategic points. Each strip was measured at five positions (center and four corners), and the mean thickness was calculated [17].

\section{Folding endurance}

The folding endurance is expressed as the number of folds (number of times of folding the strip at the same plain) required to break the specimen or developing visible cracks or folded up to 300 times manually, which was considered satisfactory to reveal good strip properties and gives an indication of brittleness of the strip [18].

\section{Drug content uniformity}

The strip was allowed to dissolve in $100 \mathrm{ml}$ phosphate buffer $\mathrm{pH} 6.8$ contained in $100 \mathrm{ml}$ volumetric flask, with stirrer maintained at $37^{\circ} \mathrm{C}$ for $3 \mathrm{~h}$ and left for $24 \mathrm{~h}$ at room temperature. The filtered solution was diluted and analyzed by UV-VIS spectrophotometer at $278 \mathrm{~nm}$ in triplicates; the average drug content was calculated [19].

\section{Surface $\mathrm{pH}$ study}

The surface $\mathrm{pH}$ of the oral dissolving strip is calculated to investigate the risk of any side effects in vivo, as acidic or alkaline $\mathrm{pH}$ may lead to irritation to oral mucosa and it is measured to uphold the surface $\mathrm{pH}$ close to neutral as possible. The strip was marginally hydrated with the help of $1 \mathrm{ml}$ of distilled water and kept for $30 \mathrm{~s}$. The $\mathrm{pH}$ was dedicated by bringing the electrode in contact with the surface of the strip and allowing it to equilibrate for $1 \mathrm{~min}$. The average of three determinations for each film was determined [20].

\section{Disintegration test}

In vitro disintegration test

The test was performed using USP disintegration test apparatus, using $250 \mathrm{ml}$ phosphate buffer $\mathrm{pH} 6.8$ at $37 \pm 0.5^{\circ} \mathrm{C}$ as a medium, $2 \mathrm{~cm}^{2} \times 2 \mathrm{~cm}^{2}$ strip was placed in the tube of the basket, and the disks were placed over it [19].
In vivo disintegration test

The time required for complete disintegration in the oral cavity was calculated from three healthy volunteers. The in vivo evaluations test was approved by the Ethics Committee of the College of Pharmacy, Mustansiriyah University. The mouth cavity was rinsed with a cup of water, the strip was placed on the tongue, and subsequently, the tongue was gently moved. The time required for disintegration in the mouth was determined. The data were represented as a mean of three determinations [21].

In vitro dissolution study

The dissolution study was carried out using USP dissolution apparatus Type II paddle apparatus in $500 \mathrm{ml}$ phosphate buffer (pH 6.8) kept at $37 \pm 0.5^{\circ} \mathrm{C}$ with rotation speed of $50 \mathrm{rpm}$. A film of $4 \mathrm{~cm}^{2}$ size was immersed in the dissolution jar, $5 \mathrm{ml}$ samples were withdrawn at the time interval from 2, 5, 10, 15, 20,30, and $45 \mathrm{~min}$ and an equal volume of the fresh dissolution media at the same temperature was replenished. The collected samples were filtered and analyzed spectrophotometrically at $278 \mathrm{~nm}$. The release parameters of chlorpheniramine maleate from strip were measured; the results were expressed as the mean of three determinations [17].

\section{Statistical analysis}

One-way analysis of the variance was chosen for statistical analysis when $\mathrm{p}<0.05$ then there would be a significant statistical difference.

\section{Variables affecting characteristics of prepared chlorpheniramine maleate pediatric oral strips}

Effect of strip forming polymer types on in vitro/in vivo disintegration time (DT) and in vitro drug release profile of prepared strips

Formulas F1-F4 were prepared to study the effect of sole polymer types (HPMC15cp, HPMC50cp, PVA, and Na CMC), respectively, at concentration of $48 \% \mathrm{w} / \mathrm{w}$ of total dry weight on the in vivo/in vitro DT and in vitro drug release parameters of chlorpheniramine maleate strips.

Effect of different plasticizer types on in vitro/in vivo DT and in vitro drug release profile of prepared strips

Formulas F1, F5, and F6 were prepared to study the effect of changing the type of plasticizer (PG, DBP, and glycerin) on in vitro/in vivo DT and in vitro drug release profile of chlorpheniramine maleate oral strips.

Effect of different concentrations of plasticizer on in vitro/in vivo DT and in vitro drug release profile of prepared strips

Formulas F6 and F7 were prepared to study the effect of changing the concentrations of plasticizer (glycerin) from $25 \%$ to $20 \% \mathrm{w} / \mathrm{w}$ of total dry weight on the in vitro/in vivo DT and in vitro drug release profile of chlorpheniramine maleate oral strips.

Effect of polymeric blend and polymeric blend ratio on in vitro/in vivo DT and in vitro drug release profile of prepared strips

Formulas F8, F9, and F10 were prepared to study the effect of polymeric blend using MD as secondary polymer at different ratio of HPMC15cp: 
MD 1:1, 1:2, and 2:1, respectively, on the in vitro/in vivo DT and in vitro drug release profile of chlorpheniramine maleate oral films.

\section{RESULTS AND DISCUSSION}

The data of physical parameters which include: Visual inspection, thickness measurement, folding endurance, surface $\mathrm{pH}$, and drug content uniformity were shown in Table 2.

\section{Visual inspection}

The appearance of all prepared chlorpheniramine maleate fast dissolving strips which contain different film-forming polymers showed homogenous, transparent, flexible, non-sticky, and smooth in the texture properties with elegant appearance.

\section{Thickness measurement}

The thickness of the strips is essential to be uniform as it is directly associated to the precision of dose. Thickness of the strips was found to vary between 0.04 and $0.23 \mathrm{~mm}$. The low \pm standard deviation (SD) values in the strip thickness measurements ensured uniformity of thickness in each formulation and the method used for the formulation of the strip is reproducible with dose accuracy.

\section{Folding endurance}

The folding endurance measures the ability of strip to withstand rupture and gives an indication of brittleness of the strip. The results showed that most of the formulas showed satisfactory folding endurance, while low folding endurance of strips below the acceptable level was found in the formulas that contain MD as secondary polymer (F8 [105 \pm 0.07$]$ and F9 [18 \pm 0.78$]$ ) this is may be due to low viscosity of polymeric solution and hence the formed films were very thin. While F10 showed, folding endurance $(>300)$ due to increased HPMC the main polymer amount [22].

\section{Drug content uniformity}

The strips prepared with various polymers were evaluated for the uniform dispersion of the drug throughout the strips. All the results indicate that the drug was uniformly dispersed throughout the films

\section{Surface pH study}

The surface $\mathrm{pH}$ of fast dissolving strips was determined to investigate the possibility of any side effects in vivo, because an acidic or alkaline $\mathrm{pH}$ may cause irritation to the oral mucosa. The surface $\mathrm{pH}$ of strips was found to be in the range of 6.21-6.9, which is within the range of salivary $\mathrm{pH}$ which indicates that there may not be any kind of irritation to the mucosal lining of the oral cavity. The SD values for all the strips were very low which indicated that the surface $\mathrm{pH}$ of all strips was uniform.

Variables affecting characteristics of the prepared chlorpheniramine maleate pediatric oral strip

Effect of strip forming polymer types on the in vitro/in vivo DT and in vitro drug release profile of prepared strips

The results of in vitro/in vivo DT of all prepared formulas were shown in Table 3. Typically, the in vivo DT is shorter than in vitro DT; this can be explained by the additional tension effect produced in the mouth by the tongue movement and the presence of saliva stimulating agent in strip composition. Four types of polymers (F1-F4) were chosen to study the influence of polymer type on in vitro/in vivo DT. The rank order of chlorpheniramine maleate oral strip in vitro/in vivo DT during this study is as follows: F3 (PVA) $>$ F2 (HPMC 50cp) $>$ F4 $(\mathrm{Na} \mathrm{CMC)}>$ F1 (HPMC 15cp), F3 shows increased in vitro/in vivo (DT) (90/82 s) in comparison with other formulas this is may be related to the increased thickness of PVA film in respect to other formulas which consecutively influenced by the viscosity of the polymer solution [23-25], while F1 showed the shortest in vitro/in vivo DT (faster disintegration 46/40 s)

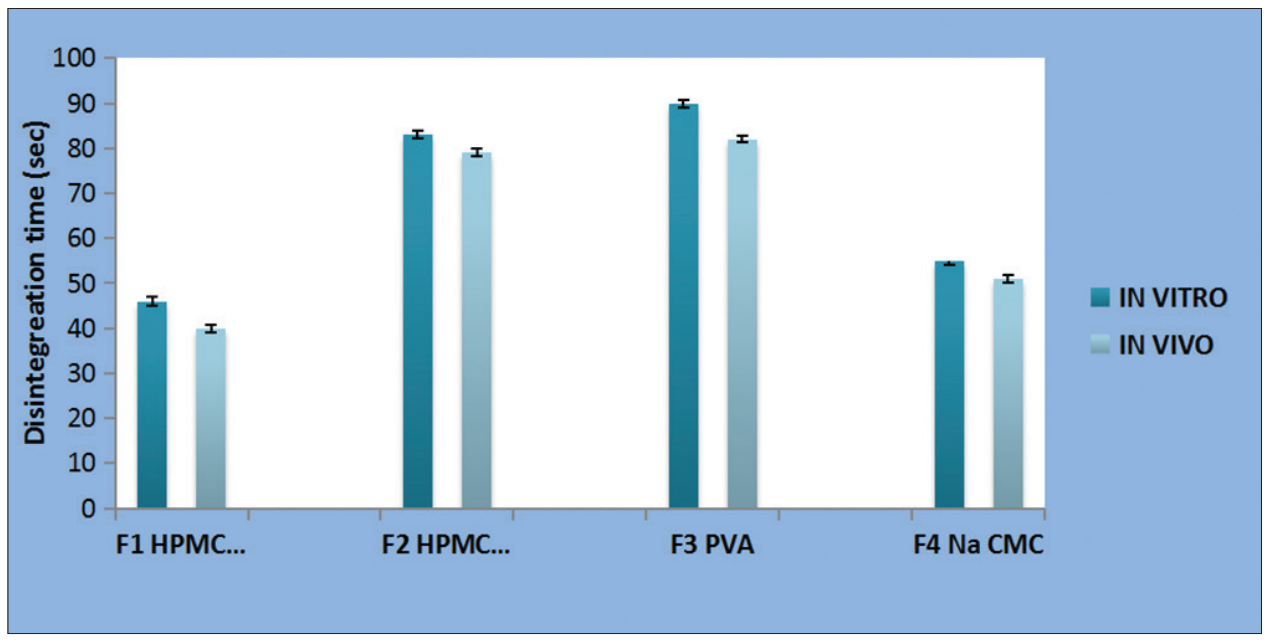

Fig. 1: The influence of sole polymer type on in vitro/in vivo disintegration time $(\mathrm{n}=3)($ mean \pm standard deviation)

Table 2: The physical parameters of the prepared oral strips of chlorpheniramine maleate

\begin{tabular}{|c|c|c|c|c|c|}
\hline Formula code & Appearance & Film thickness $\mathrm{mm} \pm \mathrm{SD}$ & Folding endurance \pm SD & Content uniformity & Surface $\mathrm{pH} \pm \mathrm{SD}$ \\
\hline $\mathrm{F} 1$ & Transparent & $0.085 \pm 0.04$ & $>300$ & $98.2 \pm 0.44$ & $6.9 \pm 0.1$ \\
\hline F2 & Transparent & $0.094 \pm 0.03$ & $>300$ & $94.23 \pm 0.3$ & $6.68 \pm 0.03$ \\
\hline F3 & Transparent & $0.23 \pm 0.062$ & $>300$ & $98.5 \pm 0.11$ & $6.8 \pm 0.08$ \\
\hline $\mathrm{F} 4$ & Transparent & $0.129 \pm 0.05$ & $>300$ & $97.8 \pm 0.13$ & $6.62 \pm 0.05$ \\
\hline F5 & Transparent & $0.091 \pm 0.08$ & $>300$ & $95.2 \pm 0.29$ & $6.78 \pm 0.03$ \\
\hline F6 & Transparent & $0.078 \pm 0.03$ & $>300$ & $95.4 \pm 0.43$ & $6.57 \pm 0.06$ \\
\hline F7 & Transparent & $0.086 \pm 0.09$ & $>300$ & $93.7 \pm 0.21$ & $6.83 \pm 0.42$ \\
\hline F9 & Semitransparent brittle in nature & $0.04 \pm 0.032$ & $18.5 \pm 0.78$ & $91.2 \pm 0.23$ & $6.61 \pm 0.01$ \\
\hline F10 & Transparent & $0.069 \pm 0.052$ & $>300$ & $98.6 \pm 0.17$ & $6.21 \pm 0.04$ \\
\hline
\end{tabular}

SD: Standard deviation 
this can be attributed to the low viscosity of HPMC15cp, in comparison to higher grade HPMC 50cp (83/79 s) and NA CMC (55/51 s), as shown in Fig. 1. A similar finding was seen in orciprenaline sulfate fast dissolving oral films [26].

Concerning in vitro drug release, Table 3 shows the release parameters for all prepared formulas. The percentage of drug being dissolved in $2 \mathrm{~min}$ (D2 $\mathrm{min}$ ) as well as the required time for releasing $80 \%$ of the drug (T80\%) was considered for determination of in vitro drug release profile. The percent drug dissolved in $2 \mathrm{~min}$ (D2 $\mathrm{min}$ ) was employed for comparison purpose due to the value of rapid drug release in case of fast dissolving oral strip preparations. The order of in vitro drug release is PVA>HPMC $15 \mathrm{cp}>\mathrm{Na} \mathrm{CMC}>\mathrm{HPMC} 50 \mathrm{cp}$, from Fig. 2; it is obvious that the F3 (PVA) showed a significant increment $(\mathrm{p}<0.05)$ in $D 2$ min value $(60.4 \%)$ and diminution in $\mathrm{T} 80 \%$ (9.9 $\mathrm{min}$ ) in comparison with other formulas this is may be resulted from erosion of loosely bounded PVA molecules on the surface due to high solubility of PVA in water [27]. A similar finding was reported in of levocetirizine dihydrochloride fast dissolving film [28]. HPMC 15cp showed the shortest DT among other polymer sorts, so it was selected for further study.

On the other hand, HPMC 50cp (F2) showed a significant diminution $(\mathrm{p}<0.05)$ in D2 $\min (40.1 \%)$ in comparison to F1 (HPMC 15cp) $(55.8 \%)$ and F3 (PVA) (60.4\%), since HPMC 50cp produces a dense and thick gel formed by a fast and rapid water uptake that retards further hydration by dissolution media which accordingly decreases the drug release [29-31]

$\mathrm{Na}$ CMC showed a significant diminution $(\mathrm{p}<0.05)$ in $\mathrm{D} 2 \mathrm{~min}$ value $(49.6 \%)$ resulted from the fact that $\mathrm{Na}$ CMC is a hydrophilic polymer, water uptake occurs rapidly, and as consequences a stable gel layer will be formed that further controls the drug release [32]. HPMC $15 \mathrm{cp}$ showed shortest disintegration time among other polymer sorts, so it was selected for further study

Effect of different plasticizer types on in vitro/in vivo DT and in vitro drug release profile of prepared strips

Dibutyl phthalate was used as plasticizer since it imparts the strength and flexibility to the strip that prevents the brittleness and breakage of the oral strip. Fig.3 showed the DT of variant types of plasticizers in which this study included; F5 showed significant increment $(\mathrm{p}<0.05)$ in in vitro/in vivo DT (88/82 seconds) among the other plasticizers, this is related to the increased physical strength of the polymeric structure caused by DBP which imparts resistance of film to break [15].

While F1 (46.2/43.8 s) and F6 (45.1/43.3 s) showed non-significant diminution $(\mathrm{p}>0.05)$ in vitro/in vivo DT this may be due to the fact that the two types of plasticizers enhanced the DT by facilitating the penetration of fluids into the strip, since plasticizer alter the densely packed chains of HPMC texture by forming the polymer structure possessing more pores and less density that breaks at lower force, resulting in faster disintegration of the film [33]

From in vitro release parameters in Table 3 , it is obvious that the formula F5 that contains DBP showed a significant diminution $(\mathrm{p}<0.05)$ in D2 min (31.8\%) and increment in T80\% (44.9 min) in comparison to other sorts of plasticizers, consequently such drug release pattern may be accredited to the variance in water permeability and leaching ability from the strip structure related to nature of plasticizer types, since DBP is hydrophobic in nature and does not undergo leaching in contrast to other two hydrophilic counterparts [34].

While F1 (55.8\%) and F6 (56.9\%) showed, non-significant increment ( $>0.05$ ) in D2 min value this may be due to that both plasticizers are water dissolvable and they will diffuse out from the strips in watery media creating void spots in the strip through which distribution of liquid happens to enable strip breaking down leading to improve release profile of drug [35], as shown in Fig. 4. According to DT and in vitro release parameters glycerin was optimized in this study.

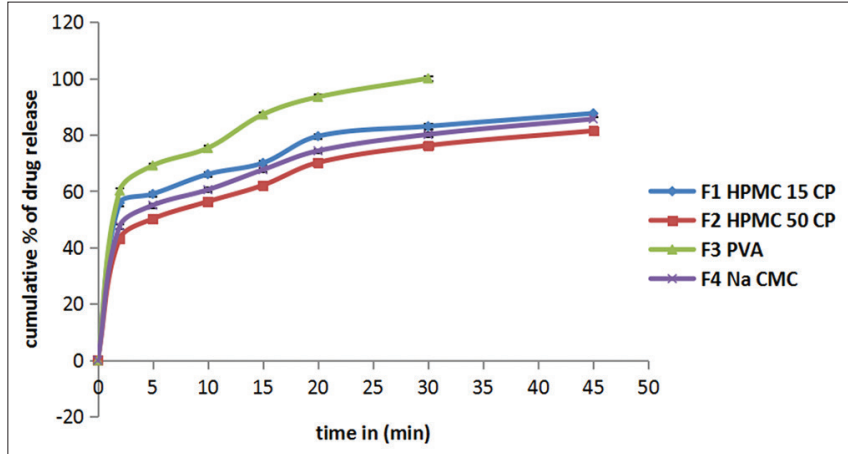

Fig. 2: Influence of sole polymer type on in vitro release profile in phosphate buffer $\mathrm{pH} 6.8$ at $37 \pm 0.5^{\circ} \mathrm{C}(\mathrm{n}=3)$ (mean \pm standard deviation)

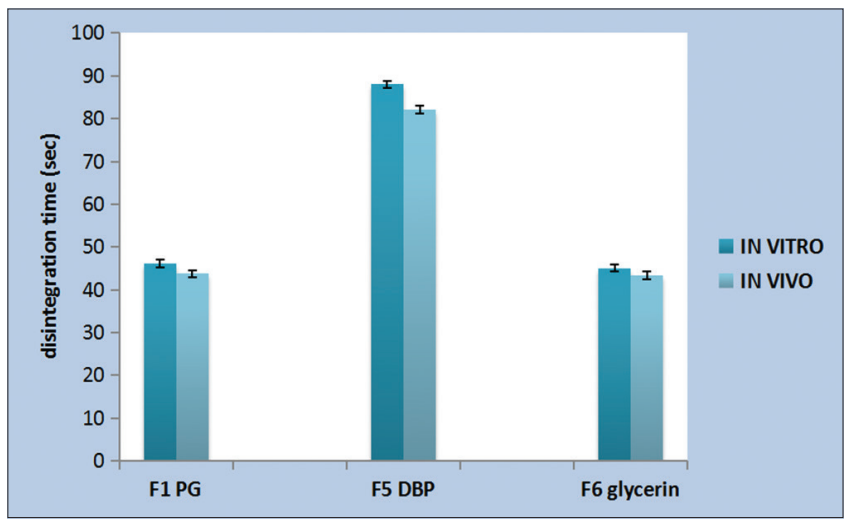

Fig. 3: Influence of different types of plasticizer in vitro/in vivo disintegration time $(n=3)$ (mean \pm standard deviation)

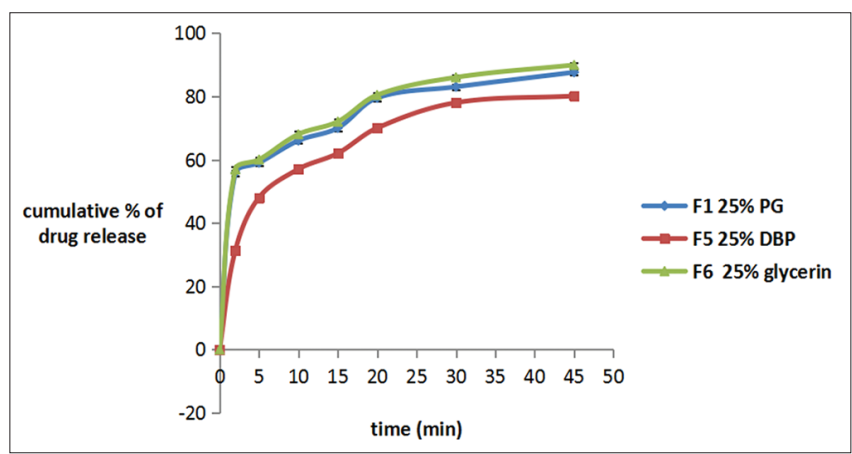

Fig. 4: Influence of different plasticizer types on in vitro release profile in phosphate buffer $\mathrm{pH} 6.8$ at $37 \pm 0.5^{\circ} \mathrm{C}(\mathrm{n}=3)$ (mean \pm standard deviation)

Table 3: The results of in vitro/in vivo DT in seconds and in vitro release parameters (D2 $\mathrm{min}$ and $\mathrm{T} 80 \%$ ) for prepared formulas $(n=3)($ mean $\pm S D)$

\begin{tabular}{lllll}
\hline $\begin{array}{l}\text { Formula } \\
\text { code }\end{array}$ & $\begin{array}{l}\text { In vitro } \mathbf{D T} \\
\mathbf{n = 3 ( s )}\end{array}$ & $\begin{array}{l}\text { In vivo } \mathbf{D T} \\
\mathbf{n = 3}(\mathbf{s})\end{array}$ & $\begin{array}{l}\mathbf{D} 2 \mathbf{m i n} \\
\mathbf{n = 3}\end{array}$ & $\begin{array}{l}\text { T80\% } \mathbf{m i n} \\
\mathbf{n = 3}\end{array}$ \\
\hline F1 & $46.2 \pm 0.04$ & $43.8 \pm 0.12$ & $55.8 \pm 0.13$ & $20.1 \pm 0.01$ \\
F2 & $83 \pm 0.76$ & $79 \pm 0.31$ & $40.1 \pm 0.03$ & $44.8 \pm 0.13$ \\
F3 & $90 \pm 0.06$ & $82 \pm 0.23$ & $60.4 \pm 0.19$ & $9.9 \pm 0.31$ \\
F4 & $55 \pm 0.13$ & $51 \pm 0.31$ & $49.6 \pm 0.16$ & $29.6 \pm 0.35$ \\
F5 & $88 \pm 0.76$ & $82 \pm 0.34$ & $31.8 \pm 0.05$ & $44.9 \pm 0.07$ \\
F6 & $45.1 \pm 0.67$ & $43.3 \pm 0.36$ & $56.9 \pm 0.02$ & $19.9 \pm 0.16$ \\
F7 & $50.3 \pm 0.87$ & $48.5 \pm 0.76$ & $40.1 \pm 0.32$ & $43.47 \pm 0.03$ \\
F8 & $42 \pm 0.07$ & $40 \pm 0.56$ & $60.4 \pm 0.12$ & $12.1 \pm 0.14$ \\
F9 & $38 \pm 0.56$ & $34 \pm 0.39$ & $62.7 \pm 0.41$ & $9.8 \pm 0.19$ \\
F10 & $40 \pm 0.14$ & $36 \pm 0.08$ & $59.9 \pm 0.43$ & $14.8 \pm 0.34$ \\
\hline
\end{tabular}

SD: Standard deviation, DT: Disintegration time 
Effect of different concentration of plasticizer on in vitro/in vivo the DT and in vitro drug release profile of prepared strips

Formula F7 was prepared to study the effect of decreasing the concentration of glycerin from $25 \%$ in F6 to $20 \%$ of total strip weight on in vitro/in vivo DT; it was noticed that when the concentration of plasticizer decreased to $20 \%$ there is a significant diminution $(\mathrm{p}<0.05)$ $(50.3 / 48.5 \mathrm{~s})$ in the in vitro/in vivo DT of oral films in comparison to F6 (45.1/43.3 s) in vitro/in vivo DT, this is maybe related to decrease the diffusion of fluid into the film, due to a less porous and more dense polymer structure which breaks at higher force, resulting in retarding disintegration of the film [36], as shown in Fig. 5.

Furthermore, it was notice that as the concentration of plasticizer decrease to $20 \%$ the release parameters D2min (40.1\%) and T80\% $(43.47 \mathrm{~min})$ showed a significant $(\mathrm{p}<0.05)$ diminution and increment in their values respectively, indicating that as the concentration of water soluble plasticizer (glycerin) decreased the number of void spaces would be decreased in the film, through which the process of diffusion

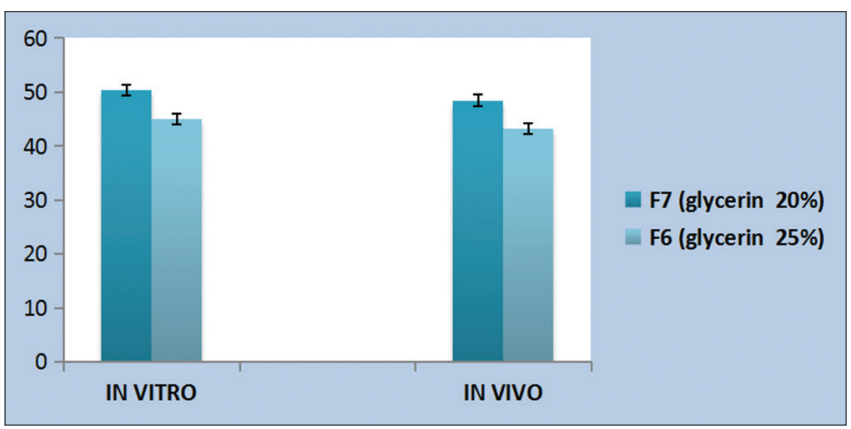

Fig. 5: The influence of decreasing plasticizer concentration on in vitro/in vivo disintegration time $(\mathrm{n}=3)($ mean \pm standard deviation) occurs, consequently less drug will diffuse out from the polymeric film [37], as shown in Fig. 6.

Effect of polymeric blend and polymeric blend ratio on in vitro/ in vivo DT and in vitro drug release profile of prepared strips

Maltodextrin is non-toxic, edible, and water-soluble film former polymer; it imparts good mouthfeel to the oral strip [38,39]. MD was incorporated in the oral strip to enhance the disintegration of strip and release profile of chlorpheniramine maleate. The effect of the incorporation of MD into the strip formulation that contains HPMC as main polymer was compared with F6 which contains HPMC as sole polymer, the effect of MD incorporated in different polymeric blend ratio in formulas F8 (1:1), F9 (1:2), and F10 (2:1) of (HPMC: MD) was shown in Fig. 7, a significant reduction $(\mathrm{p}<0.05)$ of in vitro/in vivo DT was noticed as the MD incorporated and as the ratio of maltrodextrin increased [F8 (42/40 seconds) and,F9 (38/34 seconds )] this may be related to the fact that the MD is highly water soluble which aid water penetration into the film structure; furthermore, the film with the highest amount of MD the thickness of the film would be the least; thus, the disintegration of the film will be enhanced [40]. While F10 the polymeric blend ratio of HPMC: MD is 2:1, the in vitro/in vivo DT was increased related to HPMC increased polymeric amount; hence, oral strip thickness was increased.

The in vitro release parameters revealed that the incorporation of MD into HPMC polymeric oral strip as in F8 (1:1) resulted in significant increment $(\mathrm{p}<0.05)$ in $\mathrm{D} 2 \mathrm{~min}(60.4 \%)$ and diminution in $\mathrm{T} 80 \%$ (12.1 min) in comparisim with F6 which contains HPMC as sole polymer D2 (56.9\%), T80\% (19.9 min), further moreincreasing the ratio of MD as in F9 (1:2) showed a significant increment $(\mathrm{p}<0.05)$ of D2 $\min (62.7 \%)$ and diminution of T80\% (9.8) in comparisim with F8 as shown in Fig. 8 this is related to the fact that incorporation of MD lead to decrease the viscosity of the main polymer with instant solubilization of the drug in water that lead to quicker drug release [22], while F10 which contained HPMC: MD in the ratio 2:1 resulted in significant diminution $(\mathrm{p}<0.05)$

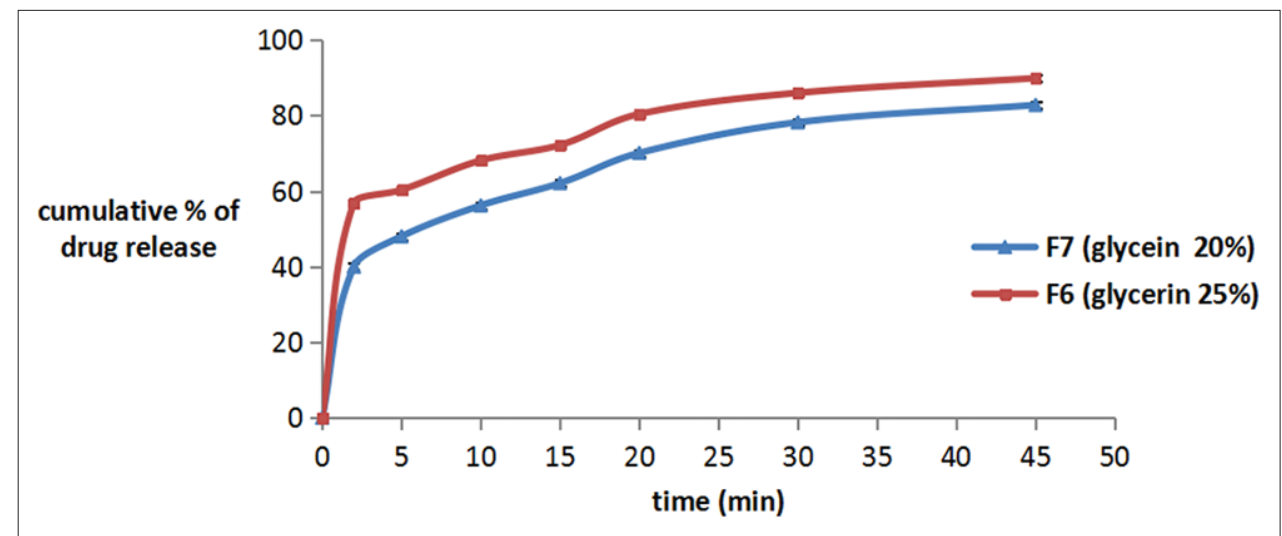

Fig. 6: Influence of decreasing the concentration of plasticizer concentration on in vitro release profile in phosphate buffer pH 6.8 at $37 \pm 0.5^{\circ} \mathrm{C}(\mathrm{n}=3)$ (mean \pm standard deviation)

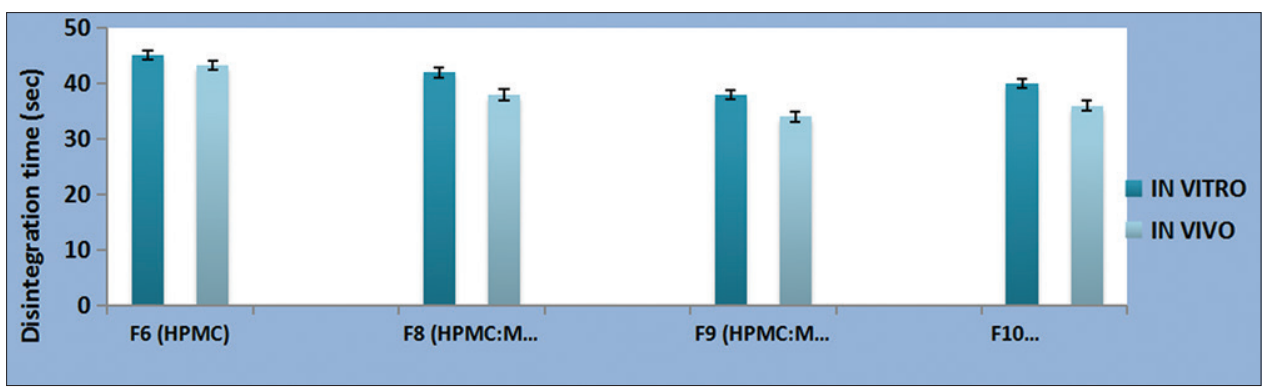

Fig. 7: Influence of polymer blend and polymeric blend ratio on in vitro/in vivo disintegration time ( $\mathrm{n}=3$ ) (mean \pm standard deviation) 


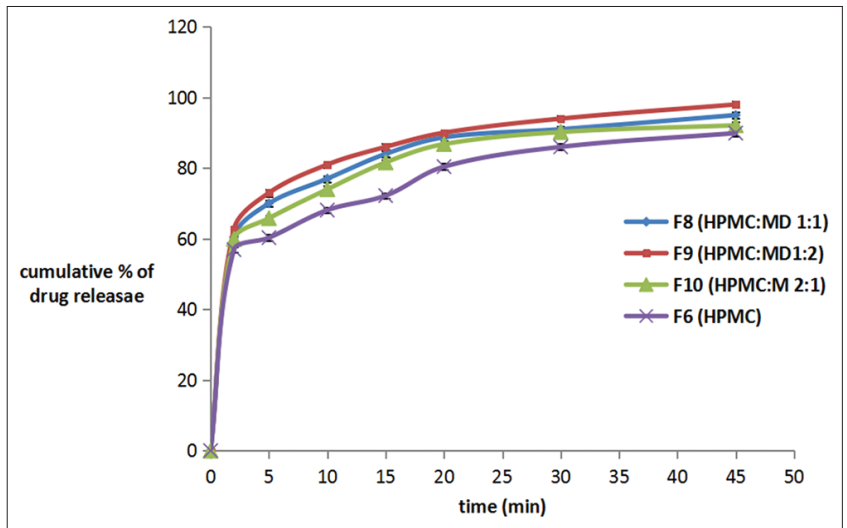

Fig. 8: Influence of polymeric blend and polymeric blend ratio on in vitro release profile in phosphate buffer $\mathrm{pH} 6.8$ at $37 \pm 0.5^{\circ} \mathrm{C}$ $(n=3)$ (mean \pm standard deviation)

in D2min (59.9\%) and increment in T80\% (14.8 min) resulted from increased HPMC polymeric amount.

Although F8 and F9 showed shorter DT and improved release parameters in comparison to F10, their mechanical properties were not satisfactory (folding endurance $<300$ ) to select them as optimize formulas. Hence, formula F10 was selected as optimum formula among those close candidates of the prepared chlorpheniramine maleate oral strip.

\section{CONCLUSION}

The overall study revealed that chlorpheniramine maleate can be prepared successfully as pediatric oral strip using different polymers solely (HPMC 15cp, HPMC 50cp, PVA, and Na CMC) and in combination with MD as secondary polymer, F10 that contains (HPMC as a main polymer and MD as a secondary polymer at the ratio [2:1]) and 25\% of glycerin as plasticizer provides satisfactory mechanical property, acceptable in vitro release profile and DT, which can be selected as optimum formula in comparison with other formulations.

\section{ACKNOWLEDGMENT}

The authors would like to express gratitude to Mustansiriyah University (www.uomustansiriyh.edu.iq) Baghdad, Iraq, for its support in the present work.

\section{CONFLICTS OF INTEREST}

All authors have none to declare.

\section{AUTHOR'S CONTRIBUTIONS}

SZM and ZDS were participated in data collection and representation. While NZY and HSS were participated in manuscript preparation and editing. All authors read and approved on the final manuscript.

\section{REFERENCES}

1. Kumari R, Priya C, Ankita K. Fast dissolving tablets: Needs to enhance bioavailability. Int Res J Pharm 2013;4:51-8.

2. Masih A, Kumar A, Singh A, Tiwari A. Fast dissolving tablets. Int J Curr Pharm Res 2017;9:8-18.

3. Bhyan B, Jangra S, Kaur M, Singh H. Orally fast dissolving films: Innovation in formulation and technology. Int J Pharm Sci Rev Res 2011;9:50-7.

4. Saini N, Nada A, Dhari J. Formulation, development and evaluation of oral fast dissolving anti-allergic film of levocetrizine di hydrochloride. J Pharm Sci Res 2011;3:1322-5.

5. Thakur N, Bansal M, Sharma N. A novel approach of fast dissolving films and their patients. Adv Biol Res 2013;7:50-8.

6. Arya A, Chandra A, Sharma V, Pathak K. Fast dissolving oral films: An innovative drug delivery system and dosage form. Int J Chem Tech Res
2010;2:576-83.

7. Kanth N, Prasad G, Kumar BV. Oral dissolving film of chlorpheniramine maleate. Int J Pharm Sci Res 2014;5:1859-73.

8. Smriti T. Mouth dissolving film: Review. Int J Pharm Bio Sci 2013;4:899-908

9. Reddy P, Varma MM, Betha S. Formulation development and characterization of chlorpheniramine maleate mouth dissolving films. Pharm Sin 2013;4:1-9.

10. Pragati B, Divya J, Archana A. Fast dissolving films of chlorphneiramine maleate. Pharm Tech Res 2014;4:207-14.

11. Dave V, Yadav RB, Ahuja R, Sahu AK. Formulation and evaluation of orally dispersible tablets of chlorpheniramine maleate by fusion method. Marmara Pharm J 2017;21:67-77.

12. Tekade BW, Jadhao UT, Patil VR, Sumit D. Formulation and evaluation of chlorpheniramine maleate fast dissolving film as antiallergic medication. Eur J Pharm Med Res 2017;4:340-5.

13. Goad A, Swamy K. Development and evaluation of fast dissolving films by using propanolol hydrochloride as a model a drug. Int J Pharm Biol Sci 2013;3:293-8.

14. Shinkar DM, Kadbhane NS, Saudagar RB. Development and evaluation of orally fast dissolving film of agomelatine. Int $\mathrm{J}$ Chem Tech Res 2017;10:497-505.

15. Yassin GE, Abass HA. Design and evaluation of oro-dispersible films of metoclopramide hydrochloride using 32 multifactorial designs. Int J Pharm Pharm Sci 2016;8:218-22.

16. Sabar MH. Formulation and in-vitro evaluation of fast dissolving film containing amlodipine besylate solid dispersion. Int J Pharm Pharm Sci 2013;15:419-28.

17. Sultana F, Arafat M, Pathan SI. Preparation and evaluation of fast dissolving oral thin film of caffeine. Int J Pharm Biol Sci 2013;3:153-61.

18. YousifNZ, Maraie NK. Optimization and evaluation of metochlopramide HCL as mucoadhesivebuccal patch. World J Pharm Res 2015;4:79-99.

19. Rahul S, Bushetti S, Shubhangi W, Bhagwat S. Development and evaluation of rizatriptan patches for buccal. World J Pharm Pharm Sci 2013;2:5020-45

20. Jaafar IS. Formulation and in vitro evaluation of fast dissolving film of metoclopramide hydrochloride. Int J Chem Tech Res 2017;10:26-38.

21. Kulkarni AS, Deokule HA, Mane MS, Ghadge DM. Exploration of different polymers for use in the formulation of oral fast dissolving strips. J Curr Pharm Res 2010;2:33-5.

22. Sri KS, Kumar CS. Development of fast dissolving oral film containing of rizatriptan benzoate as an antimigraine medication. Indo Am J Pharm Res 2013;3:2649-54.

23. Vidyadhara S, Balakrishna T, Sasidhar RL, Babu CS, Harika DL. Formulation and evaluation of zolmitriptan fast dissolving buccal films. Sch Res Lib 2013;5:145-52.

24. Raju S, Reddy PS, Kumar VA, Deepthi A, Reddy KS, Reddy PV. Flash release oral films of metoclopramide hydrochloride for pediatric use: Formulation and in-vitro evaluation. J Chem Pharm Res 2011;3:636-46.

25. Tianhong C. Enzyme-catalyzed gel formation of gelatin and chitosan: Potential for in situ applications. Biomaterials 2003;24:231-84.

26. Prabhudessai SM, Dandagi PM, Lakshman Y, Gadad AP. Development and characterization of fast dissolving oral films of orciprenalinesulphate. Indian J Pharm Educ Res 2017;51:536-42.

27. Prabhu P, Malli R, Koland M, Vijaynarayana K, Souza U, Harish NM, et al. Formulation and evaluation of fast dissolving films for delivery of triclosan to the oral cavity. AAPS PharmSciTech 2008;9:349-56.

28. Prabhu P, Malli R, Koland M, Vijaynarayana K, D’Souza U, Harish NM, et al. Formulation and evaluation of fast dissolving films of levocitirizinedi hydrochloride. Int J Pharm Investig 2011;1:99-104.

29. El Meshad AN, El Hagrasy AS. Characterization and optimization of orodispersiblemosapride film formulations. AAPS PharmSciTech 2011;12:1384-92.

30. Akbari J, Enayatifard R, Saeedi M, Saghafi M. Influence of hydroxypropyl methylcellulose molecular weight grade on water uptake, erosion and drug release properties of diclofenac sodium matrix tablets. Trop J Pharm Res 2011;10:535-41.

31. Khatoon N, Rao NG, Reddy BM. Formulation and evaluation of oral fast dissolving films of montelukast sodium. Int J Pharm Sci Res 2014;5:1780-7.

32. Qadir KA, Charyulu RN, Prabhu P, Bhatt S, Shastry CS. Formulation and evaluation of fast dissolving films of loratadine for sublingual use. Int Res J Pharm 2012;3:157-61.

33. Salman ZD, Marie NK, Alabbassi MG, Ghareeb MM. In vitro/in vivo evaluation and bioavailability study of amitriptyline hydrochloride from the optimized oral fast dissolving films. U K J Pharm Biol $2014 ; 2: 32-42$. 
34. Nayak UY, Shavi GV. Timed release of valsartan from programmable release capsules: Importance of plasticizers. Indian J Pharm Biol Res 2013;1:102-7.

35. Tamer MA, Abd-Al-Hamid SN, Ahmed B. Formulation and in vitro evaluation of bromocriptinemesylate as fast dissolving oral. Int J Appl Pharm 2018;10:7-20.

36. Chatap VK, Karale AM, Wagh P, Deshmukh PK, Patil SD, Bari SB. Fabrication of specially designed novel mold for casting of perindopril erbumine mouth dissolving film. Adv Pharmacol Pharm 2013;1:58-67.
37. Radhi AA, Kamal BA. Formulation and in-vitro evaluation of ketotifenfumarate oral strips. Int J Sci Technol 2012;7:53-63.

38. Pathare YS, Hastak VS, Bajaj AN. Polymers used for fast disintegrating oral films: A review. Int J Pharm Sci Rev Res 2013;21:169-78.

39. Parikh A, Agarwal S, Raut K. A review on applications of maltodextrin in pharmaceutical industry. Int J Pharm Biol Sci 2014;4:67-74.

40. Kumar SK, Nagabhushanam MV, Rao KR, Bhikshapathi DV. Preparation and in vivo evaluation of oral dissolving films containing sumatriptan succinate. Pham Lett 2013;5:27-38. 